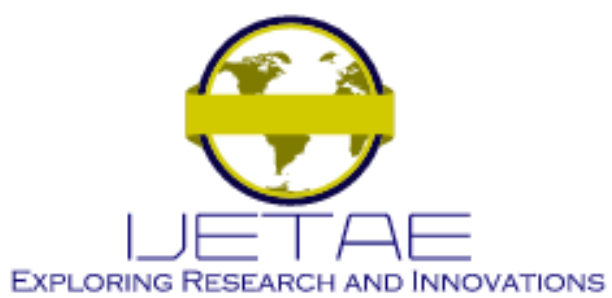

International Journal of Emerging Technology and Advanced Engineering

Website: www.ijetae.com (E-ISSN 2250-2459, Scopus Indexed, ISO 9001:2008 Certified Journal, Volume 11, Issue 10, October 2021)

Manuscript Received: 04 September 2021, Received in Revised form: 05 October 2021, Accepted: 14 October 2021

DOI: 10.46338/ijetae1021_17

\title{
Design of a System using Mobile Application for the Control of Patients with Type 1 Diabetes
}

\author{
Rosa Perez-Siguas ${ }^{1}$, Eduardo Matta-Solis ${ }^{2}$, Hernan Matta-Solis ${ }^{3}$ \\ ${ }^{1,2,3}$ Universidad María Auxiliadora \& Av. Canto Bello 431, San Juan de Lurigancho
}

\begin{abstract}
The hectic lifestyle of the human nowadays, makes them prone to have an unbalanced diet, which consists of mostly processed foods, for example: snacks, soft drinks, fried foods, among others. In the following paper, the importance of controlling the type 1 diabetes that occurs mostly in infants and adolescents will be focus, according to the Pan American Health Organization (PAHO), less than $10 \%$ correspond to this type, which until this 21 st century, there is no cure, but it is possible to have strict control so that these patients could have a better quality of life. It will focus on the control of a balanced diet and medications in which the patient is prescribed by their specialist doctor. This procedure will be done through the development of a mobile app, which is linked to a database in the hospital that the patient may be treating or doing its control, so the doctor can also have a better diagnosis and control if the patient is following with the requirements of its diet and doses of medications that doctor has been prescribing, all this data storage will be done through the mobile application developed on Android, where the patient will have a detailed schedule of their diet, glucose tests to be done and the prescription of the insulin dose.
\end{abstract}

Keywords - Type 1 diabetes, Mobile App, Smartphone, Data Management, Healthy Lifestyle.

\section{INTRODUCTION}

The International Diabetes Federation (IDF) tells that type 1 diabetes is caused by an autoimmune reaction in which the body's defense system attacks the cells that produce insulin, as a result, the body produces little or no insulin; the main causes of this are not yet known, but are linked to a combination of genetic and environmental conditions [1]. An article published in the Pan American Health Organization (PAHO) reports that people with type 1 diabetes require daily administration of insulin to regulate the level of glucose in their blood, without access to insulin such patients cannot survive, which it is usually more frequent in children and adolescents, although it can occur at any age and of the total number of people with diabetes, less than $10 \%$ correspond to type 1 [2]. About half of the deaths attributable to hyperglycemia occur before 70 years old.
According to projections from the World Health Organization (WHO), diabetes will be the seventh leading cause of death in 2030 [3].

Diabetes is a chronic disease that occurs when the pancreas can't produce insulin, or when the body cannot make good use of the insulin it produces, being a hormone produced by the pancreas, which acts as a key to allowing the glucose from the food everyone eats passes from the bloodstream to the body's cells to produce energy, all carbohydrate foods transform into glucose in the blood, insulin helps glucose enter cells [4]. Risk factors for Diabetes Mellitus Type 1 (DMT1) are still being researched. However, having a family member with Type 1 Diabetes slightly increases the risk of developing the disease [1]. Type 1 Diabetes is an inherited polygenic disease with identical 30 to $70 \%$ twin concordance, 6-7\% sibling risk, and 1-9\% risk for children who have parents with Type 2 Diabetes [4] The major sign of type 1 diabetes is very high blood sugar, which typically manifests in children as a few days to weeks of polyuria (increased urination), polydipsia (increased thirst), and weight loss. Adults with type 1 diabetes tend to have more varied symptoms that ignore on over months rather than days to weeks.

An article published in the Colegio Oficial de Enfermería of Madrid (CODEM) on the Analysis of mobile applications related to self-care for people with type 1 diabetes, indicates that [6] only 8 apps from a sample of 882 apps were relevant to this study. Although none includes functionalities that promote the totality of the 7 self-care behaviors, they do include an average of 14 criteria, with those related to the recording and interpretation of blood glucose self-monitoring being more prevalent. Social Diabetes, myDiabecticAlert and mySugr achieved the highest score [5].

A publication by the Universidad Sur Colombiana, on Design and Implementation of a Medical Prototype for the Treatment and Control of Diabetes Mellitus Type 1. 


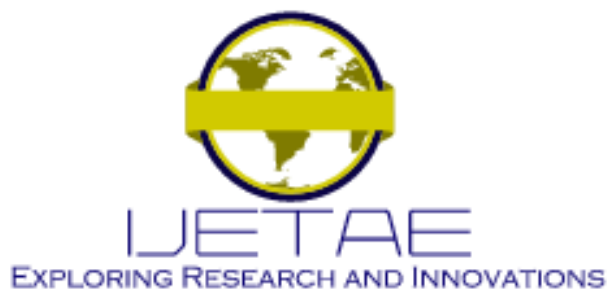

International Journal of Emerging Technology and Advanced Engineering

Website: www.ijetae.com (E-ISSN 2250-2459, Scopus Indexed, ISO 9001:2008 Certified Journal, Volume 11, Issue 10, October 2021)

It concluded that the use of "CHO QUANTIFIER" within a treatment assisted by medical professionals can lead to a significant improvement in the control of blood glucose in diabetics and when considering the monetary burden that diabetes represents from the perspective of the health system and from the perspective of the patient itself, would imply an important reduction in the financial resources allocated to the complications derived from this disease [6].

In recent years in Peru, the use of smartphones has increased, being practically a necessary means, the use of mobile applications and their functionalities to record a schedule of activities important to a person. The use of this type of mobile applications where it keeps a record of activities or event reminders apart from activity alerts are more frequently so their management is more fluid, this makes it essential in order to develop an app on the control of DMT1, doing in an effective way, simple through notifications, glucose calculator and insulin dose, also the medical enhancements, the feeding a patient with DMT1 is also taken into account and also serve for prevention notes to awareness for non-diabetic patients. Moreover, a contribution will be made to the digitization of the DMT1 patient records, since they will be uploaded to servers that have the hospitals and/or clinics where the user of the application could have a control through the use of Telemedicine. For this, in Section II, the state of art of DMT1 is shown, it has complications in a DMT1 patient will be indicated, also the complications of the COVID-19 pandemic, the effects in a patient with DMT1 will be taken into account together with the method of care required for a patient with DMT1. In the section III, the procedure which will detail the functions of the app and the scheme, explaining the way in which it performs the communication structure. In the section IV, the results of the research work will be shown, the data transfer diagram is presented. Finally, in section V, the discussion of the research work is going to be explain.

\section{State Of ART Of DMT1}

\section{A. Complications in a patient with DMT1}

DMT1 is a result from the destruction of pancreatic $\beta$ cells mediated by the immune system. Multiple genetic and environmental factors found in variable combinations in individual patients are involved in the development of DMT1 [7]. Being an autoimmune disease characterized by self-destruct mediated $T$ cells of the $\beta$ cells of the insulin secreting islets in the pancreas.
Like any other autoimmune disease, the etiology of DMT1 is complex and can result from environmental and genetic factors [8].

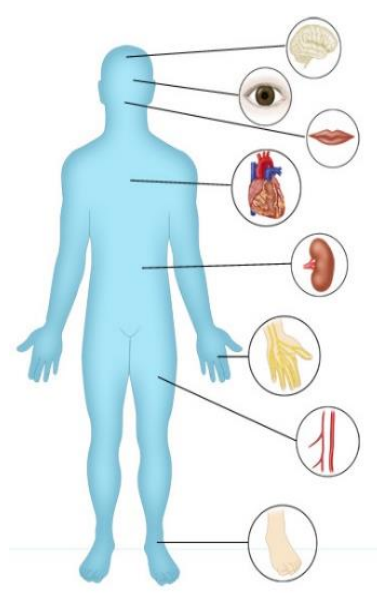

Fig. 1. Parts of the body that can be affected by complications of diabetes.

\section{B. Symptoms in a DMT1 patient}

The most common symptoms of type 1 diabetes include [1]:

- abnormal thirst and dry mouth.

- Sudden weight loss.

- Frequent urination.

- Lack of energy, tiredness.

- Constant hunger.

- Blurry vision.

- Enuresis.

Diagnosing type 1 diabetes can be difficult, so additional tests may be required to confirm a diagnosis [1].

\section{COVID - 19 in patients with DMTI}

Older people and people with pre-existing medical conditions (such as diabetes, heart disease, and asthma) appear to be more vulnerable to becoming seriously ill with the COVID-19 virus, when people with diabetes develop a viral infection, it may be more difficult to treat due to fluctuations in blood glucose levels and possibly the presence of complications from diabetes. There appear to be two reasons for this [9]. First, the immune system is compromised, making it harder to fight the virus and likely leading to a longer recovery period. Second, the virus can thrive in an environment of high blood glucose [10]. 


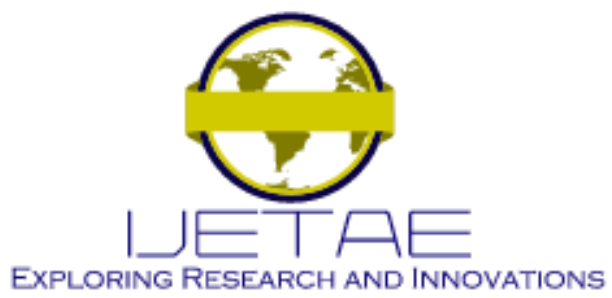

International Journal of Emerging Technology and Advanced Engineering

Website: www.ijetae.com (E-ISSN 2250-2459, Scopus Indexed, ISO 9001:2008 Certified Journal, Volume 11, Issue 10, October 2021)

\section{Nutrition in DMT1 patients}

Each person with DMT1 must be actively engaged in developing an individualized eating plan. Carbohydrate Count (CC) is a meal planning tool for patients with type 1 diabetes (T1D) treated with a basal bolus insulin regimen using multiple daily injections or continuous subcutaneous insulin infusion [10]. It is important that each member of the health care team knows the principles of nutritional therapy for people with all types of diabetes and supports their implementation [11].

The nutrition rules for children and adolescents with DMT1 do not differ from the principles of healthy eating for people without diabetes. Therefore, the demand for individual nutrients in type 1 diabetes and in healthy children is the same. Fat should be $30-40 \%$ for children up to three years old and $30-35 \%$ for children over three years old, protein $15-20 \%$, and carbohydrates (sugars) should not exceed $45-50 \%$ of the daily requirement of energy, and both in healthy people and those with DMT1 should be under control in the daily food ration [12].

\section{MethodOLOGY}

Currently, there are multiple platforms and mobile applications, such as Social Diabetes, myDiabecticAlert among others, where they provide information, advice, care and how to treat a patient with T1DM. The main difference with our approach is that our application will have the medical history of the patient in digital form, so that its treating doctor can also observe the progress of the treatment. In Figure 2, it can see the general structure of the project, in which it can observe 3 main actors, patients, family and the treating physician, each one controls specific modules, and the most important information (clinical history) is shared among all.

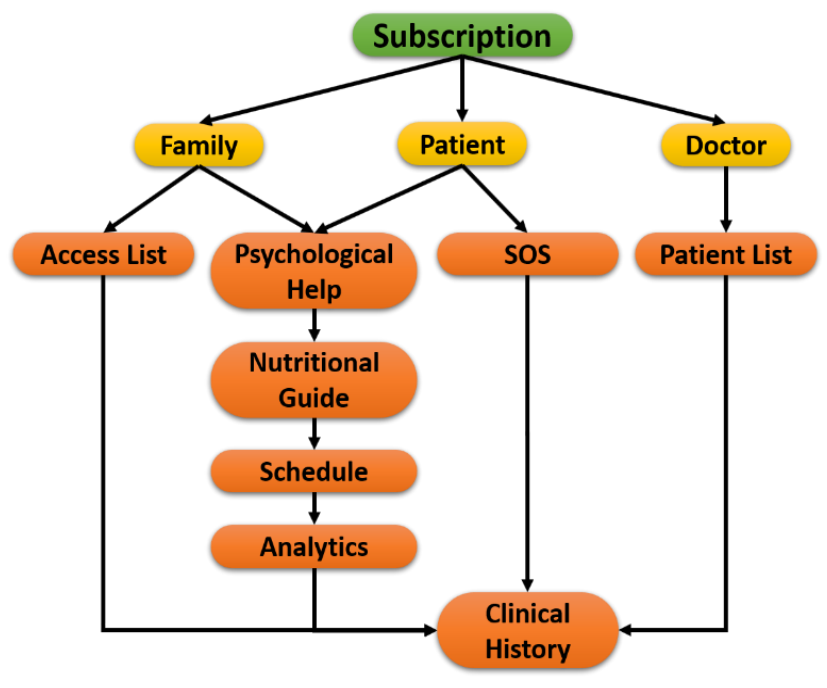

Fig. 2. General diagram of the application structure.

\section{A. Psychological help}

This section can be seen by both patients and family members, it is a very important section since patients and their relatives can decline emotionally, therefore the application will have psychological advice, motivational videos and testimony of people who already have this disease, so the patient and their family members can relax and have a normal life, the family members will be given practical advice and interactive videos on how to treat and care for a diabetic patient, with this help module the patients and their families will be guided to maintain a stable psychological profile.

\section{B. Nutritional guide}

This is a module shared by the patient and the family member, it is an important section since the nutritional does not change drastically compared to a diet of a non-diabetic person. 


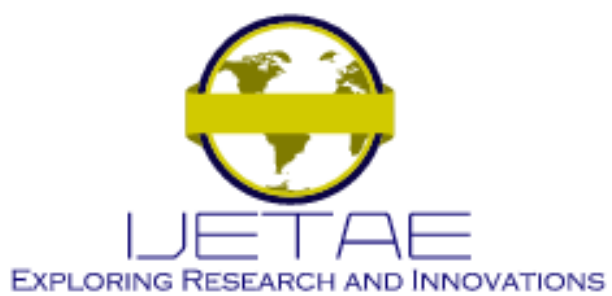

International Journal of Emerging Technology and Advanced Engineering

Website: www.ijetae.com (E-ISSN 2250-2459, Scopus Indexed, ISO 9001:2008 Certified Journal, Volume 11, Issue 10, October 2021)

The patient with DMT1 can have the same nutritional diet of a non-diabetic person who eats in a healthy way, in which compared to a person with DMT1, the count of ingested carbohydrates will be taken into account and also the count the food with its glycemic index as shown in Figure 3.

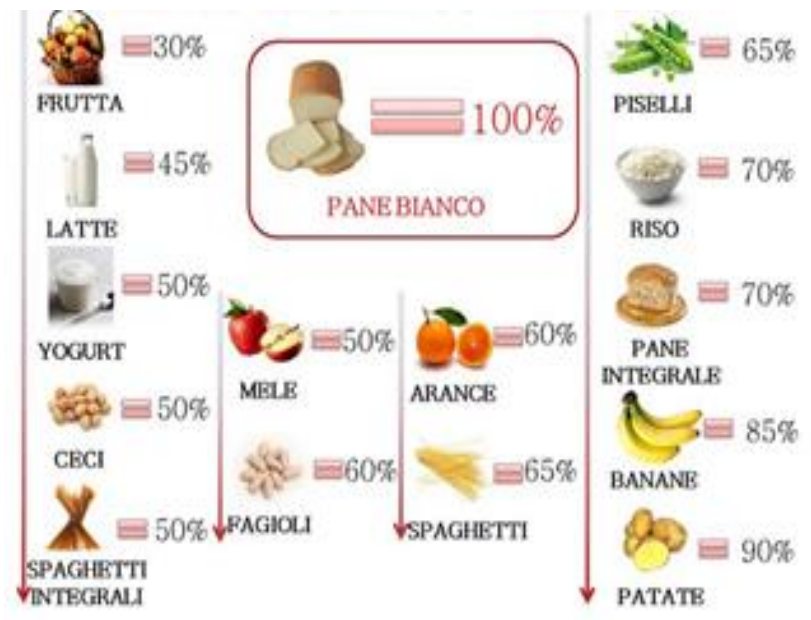

Fig. 3. Glycemic Index Average

\section{Access list}

This is a function controlled only by family members, this function allows access to the medical history generated by the platform, in this section it will find a list with all the users who have access to the patient's information. For example, this list must include the username of the treating physician, so that he / she can view the patient's history from his / her own mobile device, and the physician can also add instructions and the treatment that the patient should follow.

Using this function, the doctor can know if the patient is following the established recommendations. In this way, a quick diagnosis of any relapse that the patient may have can be made, this implies observing the history of the insulin doses that have been applied and seeing the complete record of food intake. Also, there are certain permissions that can be given to the treating physician or other family members to receive notifications of activities such as daily dose reminders, physical activities, medical appointments, motivational talks provided by the platform , and even receive SOS alerts.

\section{Schedule}

Using the platform, a schedule of daily activities of the patients can be observed, which includes a nutritional schedule, suggesting a variety of foods that involve from breakfast to dinner, also giving the glycemic index ingested in each indicated food by the platform, in addition to a reminder of insulin doses according to medical indications; the patient and family members have access to this module by default, and if the necessary permissions are given, the treating physician will be able to access; the patient is informed of the activities to be carried out through notifications on his or her cell phone, as well as the family member in charge.

\section{E. SOS Alerts}

It is suggested that the patient with T1DM should be accompanied at all times if he or she is going through critical moments, for this the platform has an SOS alert controlled by the patient, in this way he or she can request the necessary help when required; when sending an SOS alert, it will be sent to relatives and their treating doctor as well as to the entire list of people with access to this function, the notification will show the alert signal of the patient, in addition to the location of the patient thanks to the GPS from its mobile phone.

\section{F. Generalities of the Platform}

Our Platform has 3 basic modules for all users, which are: the registration and log-in module, analytics, and content.

\section{1) Registration and Log-in}

This module is shown when it starts the application, where instructions for registering or entering the platform are shown, it controls and saves all registration data and keeps the transfers already started active.

\section{2) Analytics}

This is the module in charge of creating and displaying graphs with the analysis of caloric intake, the history of insulin application, among other relevant data.

\section{3) Conntent}

The content module is an administration section, managed only to change, modify, or add content of psychological or nutritional help, for the users of the platform, this is a module administered exclusively by authorized personnel. 


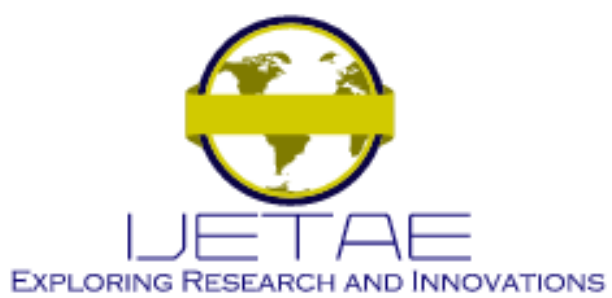

International Journal of Emerging Technology and Advanced Engineering

Website: www.ijetae.com (E-ISSN 2250-2459, Scopus Indexed, ISO 9001:2008 Certified Journal, Volume 11, Issue 10, October 2021)

The developed platform is designed based on the Model-view-controller (usually known as MVC) shown in Figure 4 where it can observe the interaction of the user with the platform, where the controller system will send the requests to the model, and the data transfer is carried out with the database, these are returned to the controller which is responsible for sending them to the view model to finally be shown to the user.

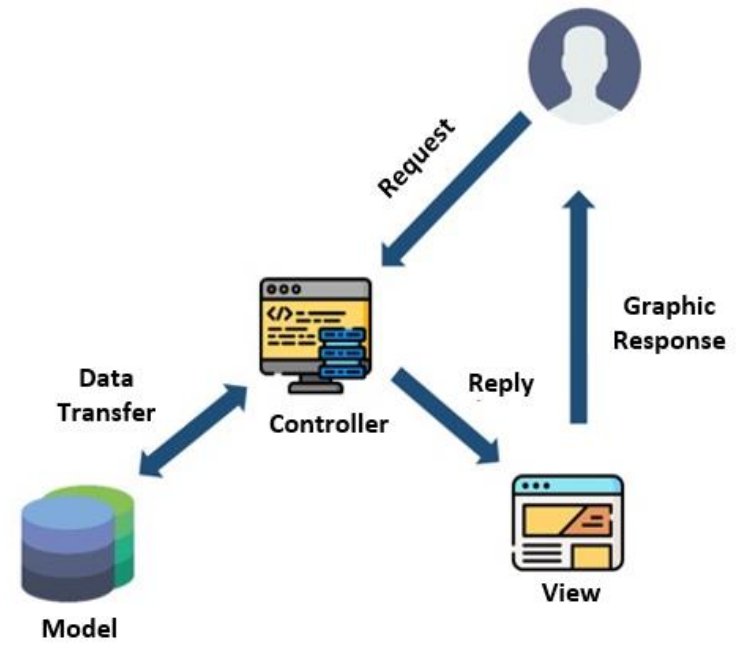

Fig. 4. Model View Controller

\section{RESULTS}

The use of the mobile platform facilitates interaction with the patient with DMT1, facilitating having a record of the daily activities that the user may be performing, providing essential information to their specialist doctor.

Being a platform with multiple functions, the user has many options in which they can interact with the platform, providing them with relevant information on registered cases of patients with DMT1, helping the user to be informed in a healthy way of the disease they are carrying.

The platform provides psychological help to both the patient with DMT1 and their relatives to be able to effectively treat the patient diagnosed with this disease.

The SOS signal implemented on the platform has a particularly important function of assisting the user so that they are treated as soon as possible, directly alerting registered family members and their treating doctor.
As part of the results obtained, a capture of the main interfaces that our application would have is shown, which it can see in Figure 5, where it shows the center the main view of the app where there is a graph with the data of the levels of glucose of the patient, on the left it can see the application menu, and finally on the right the clinical history of the patient, and something notorious that it can see in all views is the SOS button which is always available.

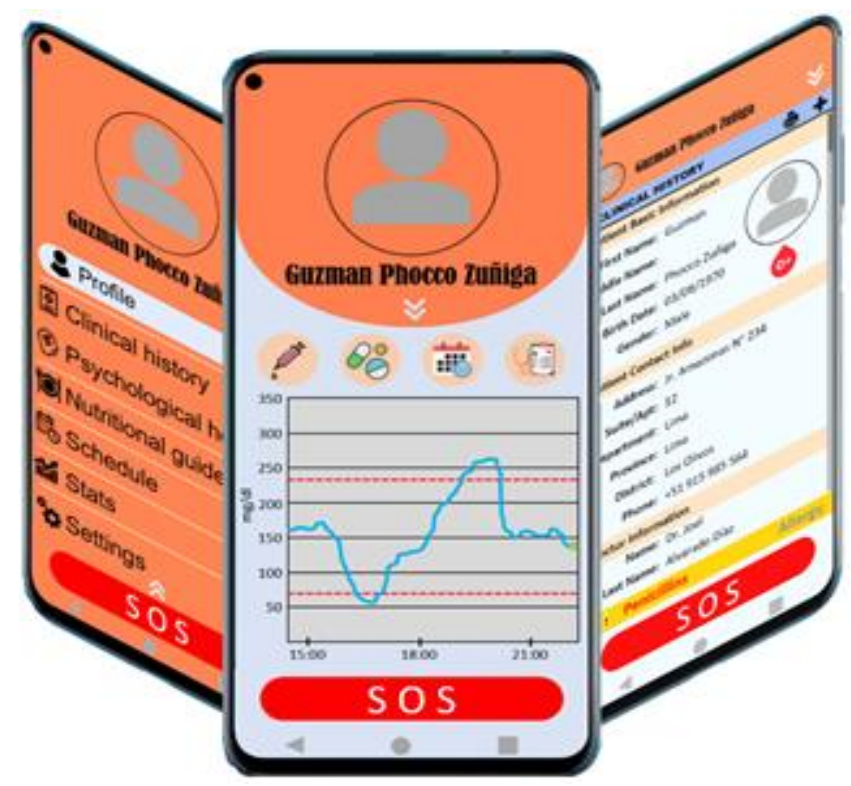

Fig. 5. Main views of the App created

\section{DISCUSSION}

Based on the studies carried out on system designs using applications, the vast majority focus on the graphic but not so much on the uses and implementations of it, so an indepth study is required on the patients involved, mapping them and knowing their needs in that moment. This paper shows a general scope of what a Type 1 Diabetic patient requires, and where it might relapse. Taking into account the symptoms, needs, requirements and treatment of a patient, an application can be generated, which is why, the María Auxiliadora University is analyzing data from patients with Type 1 Diabetes to then design and implement a mobile application and also contact medical centers for proper monitoring and analysis. 


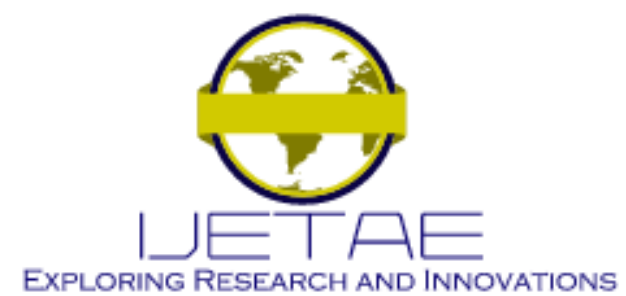

International Journal of Emerging Technology and Advanced Engineering

Website: www.ijetae.com (E-ISSN 2250-2459, Scopus Indexed, ISO 9001:2008 Certified Journal, Volume 11, Issue 10, October 2021)

\section{REFERENCES}

[1] International Diabetes Federation (2020) Diabetes tipo 1 [Online]. Available: https://www.idf.org/aboutdiabetes/type-1-diabetes.html

[2] Organizacion Panamericana de la salud (2019) ¿Qué es la Diabetes? Available:

https://www.paho.org/per/index.php?option=com_content\&view=art icle\&id=3616: diabetes\&Itemid $=794$

[3] Organizacion Mundial de la Salud (2020) Diabetes. Availible: https://www.who.int/es/news-room/fact-sheets/detail/diabetes

[4] DiMeglio LA, Evans-Molina C, Oram RA. Type 1 diabetes. Lancet. 2018;391(10138):2449-2462

[5] Monje Vigón, M. (2018). Análisis de aplicaciones móviles relacionadas con el autocuidado de personas con diabetes tipo 1. Conocimiento Enfermero, 1(01).

[6] Polo Caquimbo, C. C., Quintero Rojas, R., \& Quintero Polanco, J. D. (2015). Diseño e Implementación de un Prototipo Médico para el Tratamiento y Control de la Diabetes Mellitus Tipo 1. Ingeniería Y Región, 13(1), 191-200.

[7] Ilonen J, Lempainen J, Veijola R. The heterogeneous pathogenesis of type 1 diabetes mellitus. Nat Rev Endocrinol. 2019;15(11):635650 .
[8] Chellappan DK, Sivam NS, Teoh KX, et al. Gene therapy and type 1 diabetes mellitus. Biomed Pharmacother. 2018;108:1188-1200.

[9] I. D. F. (IDF). (2020) COVID-19 y diabetes [Online] Availible: https://www.idf.org/aboutdiabetes/what-is-diabetes/covid-19-anddiabetes/1-covid-19-and-diabetes.html

[10] Tascini G, Berioli MG, Cerquiglini L, et al. Carbohydrate Counting in Children and Adolescents with Type 1 Diabetes. Nutrients. 2018;10(1):109. Published 2018 Jan 22.

[11] Franz MJ, MacLeod J, Evert A, et al. Academy of Nutrition and Dietetics Nutrition Practice Guideline for Type 1 and Type 2 Diabetes in Adults: Systematic Review of Evidence for Medical Nutrition Therapy Effectiveness and Recommendations for Integration into the Nutrition Care Process. J Acad Nutr Diet. 2017;117(10):1659-1679.

[12] Mańkiewicz-Żurawska I, Jarosz-Chobot P. Nutrition of children and adolescents with type 1 diabetes in the recommendations of the Mediterranean diet. Odżywianie dzieci i młodzieży z cukrzycą typu $1 \mathrm{w}$ rekomendacjach diety śródziemnomorskiej. Pediatr Endocrinol Diabetes Metab. 2019;25(2):74-80. 